\title{
A PERCEPÇÃO DOS GESTORES BRASILEIROS SOBRE OS PROGRAMAS DE PREPARAÇÃO PARA A APOSENTADORIA
}

\author{
Lucia Helena de F. P. França ${ }^{1}$ \\ Cristiane Pimentel Nalin² \\ Andreia da Rocha Siqueira-Brito ${ }^{3}$ \\ Silvia Miranda Amorim ${ }^{4}$ \\ Talmo Rangel ${ }^{5}$ \\ Nanci Claudete Ekman ${ }^{6}$
}

1 Graduada em Psicologia. PhD em Psicologia. Professora titular do Programa de Pós-graduação em Psicologia (Mestrado e Doutorado) da Universidade Salgado de Oliveira - UNIVERSO, onde leciona e coordena projetos de pesquisa na área do envelhecimento, em especial sobre aposentadoria e intergeracionalidade, com o apoio da FAPERJ e do CNPq. E-mail: luciafranca@|uciafranca.com.

2 Graduada em Psicologia. Doutoranda no Programa de Pós-Graduação em Psicologia pela Universidade Salgado de Oliveira - UNIVERSO. E-mail: tianenalin@gmail.com.

3 Graduada em Psicologia. Mestranda no Programa de Pós-Graduação em Psicologia na Universidade Salgado de Oliveira - UNIVERSO. E-mail: andreiabrito35@gmail.com.

4 Graduada em Psicologia. Mestranda no Programa de Pós-Graduação em Psicologia pela Universidade Salgado de Oliveira - UNIVERSO. E-mail: silvia.miranda.amorim@gmail.com.

5 Graduado em Direito. Doutorando em Psicossociologia de Comunidades e Ecologia Social na Universidade Federal do Rio de Janeiro - UFRJ. E-mail: talmorangel@hotmail.com.

6 Graduada em Filosofia e Ciências Jurídicas e Sociais. Mestranda no Programa de Pós-Graduação em Psicologia pela Universidade Salgado de Oliveira - UNIVERSO. E-mail: nce.nce@globomail.com. 
resumo

Com o aumento cada vez mais evidente da população idosa no Brasil, diversas medidas para o bem-estar desta população foram estabelecidas na Política Nacional do Idoso e no Estatuto do Idoso. Dentre estas medidas, destacam-se os programas de preparação para a aposentadoria, apesar de muitas empresas desconhecerem esta obrigatoriedade. A presente pesquisa descritiva teve por objetivo investigar a percepção de 207 gestores - um por organização - sobre os Programas de Preparação para a Aposentadoria - PPA nas organizações. A maioria dos participantes era do sexo feminino (60\%) com média de idade de 49 anos (26 a 76 anos). Os resultados revelaram que apenas um quarto das organizações adotava o PPA, embora a maioria considerasse sua implantação relevante. Cerca da metade dos gestores respondeu que o programa deveria ser oferecido de três a cinco anos antes da aposentadoria. Quando questionados sobre as medidas que poderiam tomar frente aos trabalhadores mais velhos, a frequência foi maior das medidas que não seriam implantadas, como: a possibilidade reduzir de status hierárquico (84\%), licença extra (83\%), aposentadoria parcial - meio expediente (78,5\%), redução de carga horária (72\%). As medidas que seriam implantadas dizem respeito à possibilidade de adequação das tarefas (52,2\%), medidas ergonômicas $(50,7 \%)$ e limite de idade para um trabalho impróprio ou insalubre (44,6\%). Estes resultados apontam a necessidade de sensibilizar os gestores especialmente, os de Recursos Humanos quanto ao envelhecimento no contexto organizacional.

palavras-chave

Envelhecimento. Organizações. Gestores. Programas de preparação para a aposentadoria.

O envelhecimento se constitui em um tema emergente, implicando algumas contradições que precisam ser discutidas com a participação ampla da sociedade. Há uma diversidade de situações que devem ser analisadas pelo governo, sociedade, organizações, trabalhadores e aposentados, para que medidas sejam tomadas de forma a garantir o bem-estar dos mais velhos. Essa 
necessidade ganhou destaque com a constatação de uma transição demográfica crescente e rápida, que alterou a participação relativa dos idosos na estrutura etária populacional com o aumento, em apenas dez anos, de 9,0\% para 12,1\%. Nesse contexto, o número de pessoas com 60 anos ou mais passou de 15,5 para 23,5 milhões de pessoas, e nossa expectativa de vida deve ultrapassar os 81 anos em 2050, conforme IBGE (2012).

Entre os vários desdobramentos trazidos por essa mudança demográfica, as questões organizacionais recebem destaque apontando a necessidade de reorganização para esta nova demanda. Apesar do aumento na média de idade dos trabalhadores no mercado de trabalho, muitas empresas, até pouco tempo, estimulavam a aposentadoria antecipada para que seus quadros de pessoal fossem renovados ou enxugados. Em termos financeiros, a perda nos rendimentos daqueles que se aposentavam era pequena ou havia complementação pelos planos de pensão das organizações. Atualmente, contudo, são raras as organizações brasileiras que mantém fundos de pensão para seus empregados, e mais preocupante ainda é que apenas metade dos trabalhadores contribui para o sistema da previdência pública, de acordo com o Instituto de Pesquisa Econômica Aplicada - IPEA (2012).

Outras implicações para o mundo do trabalho dizem respeito à criação de empregos de meio período, flexibilidade de horários de trabalho, realização de pesquisas e diagnósticos antes e depois da transição para a aposentadoria. França e Stepansky (2005) reforçam que a velhice apresenta grandes desgastes físicos e mentais, no caso de trabalhadores que iniciaram no processo produtivo muito jovem, com baixos salários e péssimas condições de trabalho e de vida. Assim, é injusto que trabalhadores sejam obrigados a trabalhar além da idade limite para a aposentadoria, e este limite deve ser dimensionado também pelo tipo de trabalho desenvolvido.

A aposentadoria não é apenas uma consequência do aumento da população, desenvolvimento da industrialização, capital excedente, ou ideologia protestante, mas formada pelos aspectos sociais, políticos e culturais (LUBORSKY; LEBLANC, 2003). A aposentadoria difere do envelhecimento e a categoria de aposentados será dependente da sua área de ocupação.

Para uma compreensão melhor sobre o processo da aposentadoria nos diferentes grupos sociais, é preciso analisar o tipo e a natureza do trabalho realizado, e as diversas expectativas de vida existentes no país, consequência da desigualdade social. Muitos trabalhadores com 50 anos ou menos, principalmente os que exercem funções extremamente penosas e sacrificantes, já estão sem condições físicas para continuar a trabalhar, em sintonia com França (2009). Portanto, é preciso avaliar os conceitos de envelhecimento e de 
aposentadoria criados pelo governo quando a expectativa de vida era menor, conforme Giddens (1999). É preciso ainda verificar que existem diferentes expectativas de vida no mesmo país, e seria uma injustiça forçar a continuidade de um trabalho para uma idade que fosse muito próxima ou além da expectativa de vida local.

A definição tradicional da aposentadoria como saída definitiva da força de trabalho vem se tornando obsoleta na medida em que ela pode abrir um leque para novas oportunidades. França (no prelo) ressalta que muitos desejam continuar com uma atividade remunerada, embora a transição deva ser aproveitada para dar ao individuo maior liberdade de ser.

Para Topa e Fernandez (2014) a aposentadoria pode significar um recomeço. França (no prelo) e Menezes e França (2012) concordam com o recomeço, mas apontam que algumas pessoas querem se aposentar, apesar do receio de decidir uma vez que não têm planos para a aposentadoria. A falta de preparo para esta fase pode levar a uma série de conflitos.

Mesmo para aqueles que desejam se aposentar o planejamento para a transição é importante, dado que muitos trabalhadores argumentam que irão realizar diversos projetos, quando estimulados a defini-los, poucos são capazes de informar como tais projetos seriam desenvolvidos (FRANÇA, 2012). Neste sentido, Fonseca (2012) afirma que muitas vezes a aposentadoria, mesmo sendo previsível, chega de forma inesperada, trazendo sentimentos contraditórios. Se de um lado a pessoa ganha liberdade e o controle de sua vida, por outro lado surgem os receios e a incerteza quanto ao futuro, gerando ansiedade. Nestes casos, reside o valor dos Programas de Preparação para Aposentadoria - PPA, que ajudarão na reflexão sobre as mudanças que ocorrem com a aposentadoria.

Analisando a transição de professores universitários para a aposentadoria, Dorfman (1992) verificou que a saúde autopercebida foi o preditor mais consistente de satisfação antes da aposentadoria, enquanto que a pesquisa e o trabalho criativo eram os preditores mais consistentes de satisfação para os que já estavam aposentados. Kim e Moen (2002) investigaram as relações entre a transição para a aposentadoria e o bem-estar psicológico de homens e mulheres que ainda estavam em seus empregos ou que tinham passado para a aposentadoria. $\mathrm{O}$ fato de estar aposentado há pouco tempo (menos de dois anos) está associado ao alto nível de moral para os homens, enquanto que estar aposentado há mais tempo estava relacionado a sintomas depressivos. Da mesma forma, os estudos de Potocnic, Tordera e Peiró (2008) revelaram uma associação entre a aposentadoria involuntária e níveis mais baixos de bem-estar e satisfação com a aposentadoria. 
Palmore, George e Fillenbaum (1982) ressaltam que não são todos os estudos que suportam a relação positiva ou negativa da aposentadoria com o trabalho. Apenas quando existir outros interesses entre aqueles que estão próximos à aposentadoria, é que a relação insatisfatória com o trabalho faria com que a aposentadoria fosse priorizada. Wang (2013) e Wang, Henkens e van Solinge (2011) afirmam que a aposentadoria tem um desenvolvimento longitudinal através do qual os trabalhadores mais velhos diminuem gradativamente o seu apego psicológico em relação ao trabalho e as atividades até chegar a aposentadoria integral. Esta colocação corrobora com França (2008) quando ressaltou que as atitudes positivas ou negativas frente à aposentadoria influenciam o comportamento e a sua adaptação.

França (2008) constatou que os executivos de grandes organizações brasileiras tinham, em geral, atitudes positivas à aposentadoria, independente do fato de que a maioria estivesse satisfeita também com o trabalho. A expectativa de continuar trabalhando era mais frequente entre os trabalhadores mais jovens (até 51 anos), já que os mais velhos privilegiavam maior tempo para os relacionamentos familiares ou para o lazer (52 anos ou mais). Estes resultados podem ser interpretados pela consciência que os executivos mais velhos tinham, a de que apesar do trabalho e do status de ser executivo gerar muita satisfação e prazer, a função de executivo reduzia a convivência familiar e o lazer. Assim, este tempo roubado poderia ser resgatado na aposentadoria.

Os ganhos com a liberdade da vida sem o trabalho e a disponibilidade de um tempo que anteriormente não possuíam podem trazer consequências positivas que se remetem ao bem-estar (FRANÇA, 2008). Entretanto, o fato de o trabalhador ter 40 ou mais horas relacionadas exclusivamente ao trabalho pode também representar dificuldades na administração do novo tempo livre, na distribuição e o equilíbrio entre as atividades e o desenvolvimento de interesses e os relacionamentos afetivos e familiares.

Pesquisas recentes apontam uma relação de confiança entre o planejamento pré-aposentadoria e, posteriormente, de bem-estar. Um estudo longitudinal, realizado em aposentados americanos, indicou que aqueles que tinham discutido aposentadoria com seus cônjuges e tiveram oportunidades de planos de poupança em 1992 relataram maior bem-estar em 2004 (controlando o estado de saúde, razão para a aposentadoria, e renda de 1992). Estes resultados são pioneiros na confirmação da importância da preparação para a aposentadoria e fornecem uma base racional para o desenvolvimento mais abrangente de medidas orientadas por teorias de planejamento de aposentadoria, segundo Noone, Stephens e Alplass (2009). 
Recente revisão bibliográfica brasileira (FRANÇA et al., 2013) ressalta que a decisão da aposentadoria pode ser influenciada por preditores individuais - idade, percepção de saúde, expectativa subjetiva de vida, situação e relacionamento familiar e status financeiro), aspectos de trabalho (percepção do trabalho, controle do trabalho, flexibilidade de horário) e pelo planejamento para a transição. Para Murta et al. (2014) a decisão da aposentadoria é influenciada positivamente pelo fato da pessoa se sentir bem física e mentalmente e de ter livre arbítrio para realizar outras atividades, seja trabalho voluntário, formal ou lazer.

Na fase da decisão, estão embutidas três possibilidades tais como: a permanência do trabalhador na organização mesmo que este tenha tempo para se aposentar; o bridge employment - emprego de horário reduzido e que ocorre antes da aposentadoria definitiva, podendo representar uma ressignificação do trabalho - e o êxito final, ou a aposentadoria definitiva, de acordo com França (no prelo). Assim, o papel dos gerentes é fundamental nesse contexto, seja para apoiar os que desejam se aposentar e estão engajados em projetos pós-carreira, quanto àqueles que desejam atuar como facilitadores no repasse dos conhecimentos aos mais jovens e das novas práticas e tecnologias dos mais jovens aos mais velhos. Saber gerenciar equipes com faixas etárias diferenciadas é um desafio contemporâneo para as gestões de recursos humanos. Dentre estes novos papéis, se incluem a redução dos preconceitos frente à diversidade, entre eles os preconceitos contra os mais velhos (ageismo) nas relações de trabalho, como ressaltou França, Bendassolli, Menezes e Macedo (2013).

Segundo Van Dalen, Henkens e Schippers (2010), o que se vê em debates públicos é que os estereótipos em relação aos trabalhadores mais velhos estão profundamente enraizados no mercado de trabalho, sobretudo porque os empregadores frequentemente discriminam ou subestimam as potenciais contribuições dos trabalhadores mais velhos. Em um estudo australiano sobre a experiência de pessoas mais velhas que deixaram a força de trabalho em tempo integral de forma voluntária ou involuntariamente, Shacklock, Fulop e Hort (2007) chegaram à conclusão de que caso os gestores contribuíssem com opções de emprego flexíveis para atrair pessoas mais velhas à força de trabalho, e considerando as circunstâncias individuais, muitas pessoas mais velhas poderiam continuar trabalhando. Segundo os autores, essas pessoas mais velhas notadamente estavam dispostas a aprender coisas novas, desafiando a opinião dos empregadores de que os idosos não seriam tão flexíveis, adaptáveis ou dispostos a aprender como as pessoas mais jovens.

Seguindo as recomendações da Organização Mundial da Saúde - OMS (2002), para uma Política de Envelhecimento Saudável, o planejamento para 
a aposentadoria deve privilegiar a perspectiva da participação social, mobilidade e independência. Assim, as políticas de Recursos Humanos devem levar em consideração a permanência dos trabalhadores mais velhos que desejam continuar na organização mesmo após a idade regulamentar da aposentadoria, a implantação do PPA para aqueles que desejam se aposentar.

Nesse contexto, o PPA surgiu no final dos anos de 1980, como uma oportunidade de planejamento e de transformar esta fase num despertar de novas possibilidades, recomeço ou na otimização da própria vida. Contudo, alguns programas foram utilizados para incentivar a aposentadoria e dar lugar às fusões nas organizações. Atualmente, apesar da expansão desses programas, sua realização ainda é precária, e, apesar da legislação existente, não se sabe precisar quantas empresas realizam estes programas no Brasil, como eles são realizados, o que os diferencia e principalmente o que os gestores pensam sobre o envelhecimento no contexto organizacional.

A Política Nacional do Idoso - PNA (Lei 8.842, 1994) institui a obrigatoriedade dos PPA, sendo regulada pelo Estatuto do Idoso (Lei 10.741, 2003) recomenda a adoção do Programa de Preparação para a Aposentadoria nas organizações, bem como assegure os direitos das pessoas com idade igual ou superior aos 60 anos, inclusive em situação de trabalho. Marques, Batista e Silva (2012) sinalizam para a relevância da promoção de medidas positivas para combater os preconceitos em relação à idade, principalmente, no funcionamento do mercado de trabalho, domínio que mais contribui para a exclusão das pessoas idosas.

Como proposto por França (2012) a legislação precisa se tornar realidade, e, portanto, é fundamental que o governo não apenas proponha e fiscalize o seu cumprimento, mas se torne um parceiro neste processo educativo, envolvendo a participação dos seus Ministérios de Educação, Saúde, Trabalho e Previdência. Os gestores são elementos importantes na implantação e manutenção do PPA, uma vez que atuam também como facilitadores do projeto de vida daqueles que escolhem deixar a organização. São ainda responsáveis pelo entrosamento entre as diversas faixas etárias; do resgate e repasse de informações e da memória institucional; do (re)dimensionamento de recursos humanos e da possível reinserção do trabalhador aposentado. O que eles estão pensando sobre o envelhecimento no contexto organizacional e sobre o PPA especificamente? Que medidas estão sendo tomadas neste sentido? Para responder esta questão que ainda não foi explorada pela academia brasileira, este artigo objetiva descrever a percepção dos gestores das grandes organizações brasileiras quanto aos programas de preparação para a aposentadoria - PPA, bem como as medidas que foram adotadas, estão sendo e serão adotadas no futuro frente ao envelhecimento no ambiente organizacional. 
O presente estudo, de natureza quantitativa, descritiva e exploratória, teve por objetivo investigar a percepção de gestores sobre os Programas de Preparação para a aposentadoria - PPA nas organizações e as medidas tomadas e a serem tomadas que atendam ao envelhecimento no contexto organizacional. A pesquisa foi realizada em todo o Brasil, na qual um gestor (ou profissional que estava na época na função de gestor) de Recursos Humanos, Benefícios ou Previdência respondeu ao questionário eletrônico. Devido ao caráter descritivo e exploratório deste estudo, não houve hipóteses a serem testadas.

- Participantes - Foram convidados 2.657 gestores em todo o Brasil para participar desta pesquisa, sendo um representante por organização, exceto quando representavam uma regional distinta de uma mesma organização. Estes endereços eletrônicos foram cedidos por fundações, federações de indústria e comércio, associações e sindicatos brasileiros. Deste universo, concordaram em participar da pesquisa 207 gestores de recursos humanos, diretores e gerentes da previdência, fundos de pensão, técnicos e administradores de organizações públicas e privadas de diversos setores da economia (nível superintendência, diretoria ou gerência) de organizações com mais de 500 empregados em todo o país.

- Instrumento - O instrumento foi adaptado do questionário ASPA (Activating Senior Potential in Ageing Europe), utilizado em um projeto similar realizado em diversos países europeus por Van Dalen, Henkens e Schippers (2010). Contudo, foram acrescidas questões relacionadas aos Programas de Preparação para a Aposentadoria (PPA), que originalmente não foram abordadas no questionário da ASPA, mas que são relevantes para a nossa realidade, com base em pesquisas anteriores de França (2008) e França et al. (2009).

Após a autorização dos autores do ASPA, foram seguidos os procedimentos recomendados internacionalmente para a tradução e adaptação de algumas questões no questionário de pesquisa. A retrotradução destas questões foi efetuada para a língua portuguesa por uma brasileira e um inglês, nativos, respectivamente fluentes na língua inglesa e portuguesa, a fim de conservar a equivalência semântica e conceitual das questões, além da adaptação cultural a nossa realidade.

O questionário final contou com 45 questões, que abordaram os seguintes aspectos: dados sobre a organização; empregabilidade; gerência de recursos humanos; trabalhadores mais velhos e envelhecimento; o futuro do mercado de trabalho e as políticas de emprego e dados demográficos. No escopo 
deste artigo, não apresentamos escalas, nem tampouco a validação das mesmas foram necessárias, sendo focalizadas, descritivamente, a percepção dos gestores brasileiros frente às políticas organizacionais voltadas para estes trabalhadores mais velhos e aos Programas de Preparação para a Aposentadoria.

- Procedimentos - O projeto, os instrumentos da pesquisa e seus procedimentos foram submetidos e aprovados pelo Comitê de Pesquisa e Ética da universidade em 13 de abril de 2011 sob o no 10/2011. Um banco de dados foi formado por 2.657 endereços eletrônicos de gestores de grandes empresas cedidos por associações, federações brasileiras de indústria e comercio, sindicatos. Ainda que a equipe tenha tentado exaustivamente a representatividade em contatar todas as organizações solicitando endereços por meio de associações, sistema S, sindicatos, bem como a Associação Brasileira de Recursos Humanos (ABRH) e a Associação Brasileira das Entidades Fechadas de Previdência Privada (ABRAPP), não foi possível precisar o percentual de resposta dos respondentes com as instituições que forneceram os endereços, pois os questionários eram anônimos. A ABRH, por exemplo, apesar de ter participado da pesquisa, não cedeu diretamente os endereços, mas colocou no site e tivemos que criar um código específico para eles, não sendo possível realizar follow-ups ou calcular representatividade. No caso da ABRAPP, o link da pesquisa foi enviado para seus associados, mas é difícil precisar a taxa de retorno de cada uma destas instituições. Conseguir dados sobre organizações é quase impossível no Brasil, já que algumas delas não inserem em seus sites nem endereço nem e-mail dos gestores. Contudo, foram enviados 2.657 questionários (um por organização) e retornaram 207 respondentes, o que dá uma taxa de retorno de 7,8\%.

Uma empresa especializada foi contratada para a realização da coleta e armazenamento dos dados criando um link de pesquisa que foi enviado eletronicamente aos participantes, onde eles abririam um questionário online. Foram enviados em média quatro follow-ups para estes gestores, por meio de e-mails e telefonemas. A coleta de dados durou cerca de dois meses.

Após a coleta e a limpeza de banco dados, a análise dos dados foi realizada através do pacote estatístico Statistical Package for the Social Science - SPSS, versão 19. Primeiramente, foram realizadas análises descritivas e algumas correlações com os dados sociodemográficos dos participantes (gênero e grupo etário) e os tipos de organizações (públicas vs. privadas). 


\subsection{Perfil dos participantes}

Ao final da coleta de dados, 207 participantes responderam o mínimo 75\% das questões. A taxa de retorno foi em 7,8\%, que, apesar de baixa, consideramos representativa para gestores de grandes organizações brasileiras. A maior parte dos participantes era do sexo feminino (60\%). A faixa etária variou entre 26 e 76 anos, sendo a média de idade 47 anos (DP $=8,73$ ) e a mediana de 48,5 anos. A mediana foi utilizada como ponto de corte dos grupos etários. Assim, os participantes que tinham até 49 anos inclusive formaram o grupo dos mais jovens, e aqueles com 50 anos ou mais fizeram parte do grupo dos mais velhos.

Mais da metade (52,3\%) dos participantes eram gestores e um quarto (25,6\%) foi formada por técnicos de nível superior. Pouco menos de um quinto $(18,6 \%)$ agrupou diretores e uma pequena parcela $(3,5 \%)$ ocupava o cargo de diretor geral, reitor ou presidente. Estes gestores, técnicos e diretores atuavam na área de gestão de recursos humanos, previdência ou benefícios, por conta disso, estes participantes serão chamados de gestores.

Quanto à natureza das organizações, a amostra foi composta por mais gestores do setor privado (60\%). Quando subdivididos por setores econômicos, um quarto dos gestores era do setor da previdência (28 participantes), que representavam as unidades ou superintendências da previdência pública de todo o Brasil (INSS). Outro setor que se destacou foi o da educação (16\%), seguido por outros (14\%), da administração pública (13\%) e da indústria (9\%).

A idade de 60 anos foi considerada ideal para a aposentadoria percebida pelos gestores. Grande parte (60\%) avaliou que uma pessoa com 65 anos estaria muito velha para trabalhar 40 horas semanais.

\section{Aposentadoria}

No que diz respeito aos itens relacionados à aposentadoria, a idade pretendida para a aposentadoria variou entre 44 a 80 anos, sendo que a média de idade para a aposentadoria foi de 60 anos (DP =7,34). A maioria dos respondentes $(78,2 \%)$ considerou que até aos 55 anos (inclusive) uma pessoa ainda é considerada muito jovem para se aposentar e grande parte dos participantes (64\%) considerou ainda que a partir de 60 anos (inclusive) os trabalhadores devem reduzir a carga horária de trabalho. 
A maior parte das organizações $(63,1 \%)$ não possui fundo de aposentadoria complementar (fundos de pensão).

\subsection{Programa de preparação para a aposentadoria}

A maioria dos gestores $(82,5 \%)$ considera que os programas de preparação para a aposentadoria estão entre os status importantes e muito importantes. Contudo, apenas $23 \%$ das organizações pesquisadas desenvolvem estes programas.

a. Articulação entre o PPA e associação de aposentados;

Das $23 \%$ das organizações (48) que possuem o PPA, apenas $40 \%$ realizam o programa em articulação com a associação de aposentados.

b. Tempo de ingresso no PPA;

Quanto ao tempo que os gestores percebem como ideal para a participação em um programa, quase a metade (49\%) assinalou que seria de 3 a 5 anos. Outra parte (45\%) dos gestores admitiu que o ideal seria entre 1 a 2 anos, e apenas $6 \%$ indicou que o tempo para o ingresso no PPA poderia ser menor que um ano.

\subsection{Etapas do PPA realizadas pelas organizações}

A tabela 1 representa as etapas contidas nos Programas de Preparação para a Aposentadoria das organizações. As mais destacadas pelos gerentes foram as palestras informativas $(25,4 \%)$, o diagnóstico de interesses e anseios $(25 \%)$, seguidas pelos grupos de reflexão $(19,6 \%)$. Poucas empresas $(9,1 \%)$ realizam o acompanhamento dos aposentados após saírem da organização, e são raras as organizações que avaliam o programa após seis meses de saída do trabalhador $(6,7 \%)$, após um ano $(5,3 \%)$ ou após dois anos $(2,4 \%)$. 
Tabela 1 - Etapas do PPA

\begin{tabular}{l|c}
\hline \multicolumn{1}{c|}{ Etapas do PPA } & $\%$ \\
\hline Palestras informativas & 25,4 \\
\hline Diagnóstico de interesses e anseios & 25 \\
\hline Grupos de reflexão & 19,6 \\
\hline Dinâmicas vivenciais & 18,7 \\
\hline Workshops & 16,7 \\
\hline Acompanhamento até a decisão da aposentadoria & 13,9 \\
\hline Aproveitamento do pré-aposentado como multiplicador dos conhecimentos & 10 \\
\hline adquiridos na empresa & 9,1 \\
\hline Acompanhamento após a saída do trabalhador & 6,7 \\
\hline Avaliação após seis meses de aposentado & 5,3 \\
\hline Avaliação do programa pelos aposentados após um ano & 4,3 \\
\hline $\begin{array}{l}\text { Outras etapas: treinamento para gerência, nutrição e educação financeira, } \\
\text { encontro de aposentados, curso de empreendedorismo, ampliação do programa } \\
\text { para todos servidores, abono de permanência. }\end{array}$ & 2,4 \\
\hline Avaliação do programa pelos aposentados após dois anos & \\
\hline
\end{tabular}

Nota: $N=200$

\subsection{Valorização do profissional em função do tempo de serviço nas organizações}

Com relação à possibilidade de valorização do profissional em função do tempo de serviço nas organizações, grande parte (68\%) dos participantes considera importante a compensação por tempo de serviço, ou seja, na medida em que os trabalhadores permaneçam fiéis à organização, devem receber um aumento gradativo em seus salários.

\subsection{Formas de aprendizagem consideradas mais importantes para as organizações}

A Tabela 2 apresenta as formas de aprendizagem consideradas mais importantes para as organizações. Dentre as formas de aprendizagem mais votadas estão os cursos de capacitação e os cursos de atualização, seguidas pela 
aprendizagem com os trabalhadores mais velhos e aprender fazendo, todas avaliadas como importantes (média superior a 3,5). A forma de treinamento menos votada foi aprender com os recém-formados.

Tabela 2 - Formas de aprendizagem consideradas mais importantes para as organizações

\begin{tabular}{l|c}
\multicolumn{1}{c|}{ Formas de Aprendizagem } & M \\
\hline Realizar cursos de capacitação & 3,8 \\
\hline Realizar cursos de atualização & 3,8 \\
\hline Realizar cursos de formação/especialização & 3,7 \\
\hline Aprender com os trabalhadores mais velhos & 3,7 \\
\hline Aprender fazendo & 3,6 \\
\hline Aprender com os recém-contratados & 2,8 \\
\hline
\end{tabular}

Nota: As variações da relevância das formas de aprendizagem vão de 1 = nada importante a 4 = muito importante.

\subsection{Medidas de Recursos Humanos (RH) destinadas aos trabalhadores mais velhos}

Quando os gestores foram questionados sobre as medidas que poderiam tomar, especificamente em função dos trabalhadores mais velhos, a frequência maior foi concentrada nas medidas que não serão aplicadas, pois obtiveram a adesão da maioria ( $70 \%$ ou mais dos participantes), tais como: as possibilidades de redução de status hierárquico (84\%), as possibilidades de licença extra (83\%), aposentadoria parcial - meio expediente $(78,5 \%)$, diminuição de carga horária $(72 \%)$, redução de horário de trabalho $(70 \%)$ e esquemas de aposentadoria antecipada $(70 \%)$. Dentre as medidas que deverão ser consideradas no futuro destacam-se as ergonômicas (51\%), a possibilidade de adequação das tarefas (52\%), o limite de idade para um trabalho impróprio ou insalubre (45\%) e o treinamento para trabalhadores mais velhos (44\%), medidas que denotaram mais de $40 \%$ de adesão dos gestores. Por fim, a progressão continua na carreira (41\%) e as medidas ergonômicas (31\%) são as ações que já foram adotadas e que obtiveram mais de $30 \%$ de adesão dos gestores. A Tabela 3 destaca as medidas destinadas aos trabalhadores mais velhos aplicadas atualmente, as que devem ser consideradas no futuro próximo e as que não serão consideradas. 
Tabela 3 - Medidas destinadas aos trabalhadores mais velhos, aplicadas atualmente, as medidas consideradas no futuro próximo e as que não serão consideradas

\begin{tabular}{l|c|c|c}
\hline \multirow{2}{*}{ Medidas } & $\begin{array}{c}\% \\
\text { Atualmente }\end{array}$ & \multicolumn{2}{c}{$\%$} \\
\cline { 2 - 4 } & $\begin{array}{c}\text { Já } \\
\text { aplicada }\end{array}$ & $\begin{array}{c}\text { Será } \\
\text { considerada }\end{array}$ & $\begin{array}{c}\text { Não será } \\
\text { considerada }\end{array}$ \\
\hline a. Aposentadoria parcial (meio-expediente) & 2 & 19,5 & $\mathbf{7 8 , 5}$ \\
\hline $\begin{array}{l}\text { b. Redução de horário de trabalho antes } \\
\text { da aposentadoria }\end{array}$ & 1,5 & 28,4 & $\mathbf{7 0 , 1}$ \\
\hline $\begin{array}{l}\text { c. Regras de treinamento para trabalhadores } \\
\text { mais velhos }\end{array}$ & 7,3 & $\mathbf{4 4 , 4}$ & $\mathbf{4 8 , 3}$ \\
\hline $\begin{array}{l}\text { d. esquemas de aposentadoria antecipada } \\
\text { e. Possibilidades de licença extra para }\end{array}$ & 9,3 & 21 & $\mathbf{6 9 , 8}$ \\
\hline trabalhadores mais velhos & 2,5 & 14,8 & $\mathbf{8 2 , 8}$ \\
\hline $\begin{array}{l}\text { f. diminuição de carga horária para } \\
\text { trabalhadores mais velhos }\end{array}$ & 3,4 & 25 & $\mathbf{7 1 , 6}$ \\
\hline $\begin{array}{l}\text { g. Redução de status hierárquico } \\
\text { h. Medidas ergonômicas }\end{array}$ & 2,5 & $\mathbf{1 3 , 5}$ & $\mathbf{8 4}$ \\
\hline $\begin{array}{l}\text { i. Limite de idade para um trabalho impróprio } \\
\text { e/ou insalubre }\end{array}$ & 24,8 & $\mathbf{4 4 , 6}$ & $\mathbf{3 0 , 7}$ \\
\hline \begin{tabular}{l} 
j. Possibilidade de adequação das tarefas \\
\hline k. Progressão contínua na carreira
\end{tabular} & $\mathbf{2 8 , 1}$ & $\mathbf{5 2 , 2}$ & $\mathbf{1 6 , 7}$ \\
\hline \begin{tabular}{l} 
I. Horário de trabalho flexível \\
\hline
\end{tabular} & $\mathbf{4 0 , 8}$ & $\mathbf{3 2 , 3}$ & $\mathbf{1 6 , 9}$ \\
\hline
\end{tabular}

Nota: Estão assinaladas em negrito as tendências de endereçamento das medidas acima de 30\%.

\section{Discussão}

Nos últimos 20 anos, trabalho e aposentadoria não estão sendo mais considerados conceitos opostos, conforme Cahill, Giandrea e Quinn (2013). Os resultados dessa pesquisa reforçam essa tendência, a começar pela maioria dos participantes ter considerado que aos 55 anos uma pessoa ainda é jovem para se aposentar e, que a partir dos 60 anos é preciso considerar a redução de carga horária.

A existência de um futuro agora alongado estimulou a criação de empresas de previdência complementar. Assim, diversas fundações vinculadas às empresas estatais foram implantadas e, de forma mais tímida, foram expandidas para as instituições privadas. Estas empresas administram os fundos de pensão para seus colaboradores, que após uma carência de 
participação, complementam a pensão do sistema público. Seguindo esta tendência e novo nicho de mercado, no final do século passado os bancos privados passaram a oferecer planos de previdência (PGBL ou VGBL), como forma de poupança individual para a aposentadoria. Apesar disso, nesta pesquisa a maior parte dos gestores relatou não possuir fundo de pensão em sua organização.

Há um consenso acadêmico em considerar a aposentadoria não como um único evento, mas como um processo que se desenvolve ao longo de anos, como reforçado por Shultz e Wang (2011). A maioria dos gestores brasileiros (82,5\%) considerou o PPA entre importante e muito importante. Contudo, apenas $23 \%$ das organizações pesquisadas desenvolvem este programa.

Apesar de serem poucas as organizações que adotam estes programas, notadamente as do setor público, algumas têm realizado o programa há mais de vinte anos, outras implantaram o PPA há menos de cinco anos. Dentre as organizações que mais tem se destacado na abrangência deste trabalho se destacam a Petrobras, Furnas, Vale, Serpro, governos estaduais, como a Bahia com uma dezena de edições do Programa Prepare-se que se espalhou em diversos municípios, tribunais e universidades em todo o Brasil. Das universidades vale destacar a Universidade Federal de Santa Catarina (UFSC), que iniciou o PPA há mais de 30 anos (ZANELLI; SILVA, 1995) e foi continuado pelo programa denominado Aposent-ação (SOARES; COSTA, 2011). Como trabalho recente deve ser destacado a Universidade de Brasília, engajada no preparo de multiplicadores para implantar o programa administrado para seus servidores, conforme assinalado por Murta et al. (2014).

Com essa pesquisa constata-se que o modelo de PPA brasileiro é baseado em palestras informativas, diagnóstico de interesses e anseios, e grupos de reflexão, o que corrobora com os estudos de França (2002) e Zanelli, Soares e Silva (2010). Poucas empresas realizam o acompanhamento dos aposentados, após saírem da organização e, raramente, as organizações avaliam o programa após seis meses ou após um ou dois anos da saída do trabalhador. Essa constatação nos leva a questionar se os programas implementados atualmente têm conseguido cumprir com o objetivo proposto pela literatura, segundo Alcover, Topa e Fernàndez (2014) frente à redução gradual do apego psicológico ao trabalho até chegar à aposentadoria integral. Em um dos Programas de Preparação para o Período Pós-carreira do Governo do Distrito Federal, a maioria dos participantes, apesar de já estar apta para se aposentar imediatamente, pretendia solicitar o abono permanência por não terem se planejado para esse processo, principalmente quanto ao aspecto financeiro, como visto em Marangoni e Mangabeira (2014). 
Quanto às medidas de Recursos Humanos apontadas pelos gestores para os trabalhadores mais velhos, encontram-se medidas não contempladas pela nossa legislação trabalhista como: aposentadoria parcial e redução da carga horária e que precisam ser reformuladas frente a este novo perfil demográfico brasileiro. As medidas ergonômicas e de treinamento destacaram-se entre as que deverão ser consideradas no futuro, sendo que atualmente os gestores apontaram que são efetuadas apenas medidas ergonômicas e de progressão continuada na carreira. Esta é a principal diferença observada entre as medidas de RH entre os gestores brasileiros e europeus. Van Dalen et al. (2010) assinalam que as medidas implantadas por grande parte dos gestores europeus (56\%) foram relacionadas a acomodar os trabalhadores mais velhos no mercado de trabalho e quase metade (49\%) das medidas ergonômicas estava relacionada a trabalho de meio período ou a antecipação gradual da aposentadoria, usando a redução de carga de trabalho.

Tais resultados revelam que os Recursos Humanos precisam adotar não apenas medidas ergonômicas, mas o estimulo à educação permanente e a atualização dos trabalhadores mais velhos, bem como a quebra dos preconceitos contra o envelhecimento, sobretudo porque há uma tendência permanecerem trabalhando, como assinalado por Teh (1999) e por Armstrong-Stassen (2008).

\section{Conclusão}

Os resultados dessa pesquisa contribuíram para esclarecer como os gestores brasileiros veem os Programas de Preparação para a Aposentadoria, sejam eles realizados nas organizações em que estão inseridos ou não. Apesar do seu pioneirismo, seus resultados são limitados a uma analise descritiva. Assim, pesquisas aprofundadas precisam ser realizadas nesta temática no sentido de contribuir para o avanço acadêmico e subsidiar as normas e ações em Recursos Humanos, estabelecendo uma ponte entre a universidade e as organizações, onde o processo de envelhecimento seja de fato incluído em suas políticas.

Programas de Preparação para a Aposentadoria, apesar de serem considerados importantes pelos gestores, ainda estão longe de ser uma prática em geral nas organizações. Por este motivo, torna-se imprescindível a sensibilização dos gestores quanto à relevância de apoiarem os trabalhadores nesta transição, visando o seu bem-estar. Além do PPA, a ampliação da expectativa de vida requer um mercado com profissionais qualificados, assim trabalhadores 
mais velhos precisam ser treinados e atualizados, permanentemente, numa perspectiva de desenvolvimento integral, para que possam permanecer competitivos no mercado de trabalho, especialmente se eles quiserem se continuar trabalhando mesmo após a idade da aposentadoria. França (no prelo) ressalta que o patrimônio é algo que leva muito tempo para ser construído, e por maior que seja o valor da tecnologia que os mais jovens dominam com facilidade, a história foi criada por aqueles que a vivenciaram.

Finalmente, é necessária uma mobilização não apenas dos gestores, mas dos legisladores e sensibilizá-los quanto ao envelhecimento no contexto organizacional, de forma a fornecer o apoio necessário aos que desejam se aposentar por meio do PPA, bem como permitir a continuidade dos trabalhadores mais velhos no mercado de trabalho aos que desejam permanecer trabalhando, principalmente em horários reduzidos. Nesse sentido, devem ser incentivados tanto os projetos de equilíbrio vida-trabalho, quanto a adoção das oportunidades de atualização, flexibilidade dos horários, controle do trabalho e a adoção de medidas ergonômicas. As organizações precisam preparar seus quadros de pessoal para substituir aqueles que irão se aposentar e o desenvolvimento da carreira mais alongada para os trabalhadores que queiram continuar além da idade regulamentar para a aposentadoria.

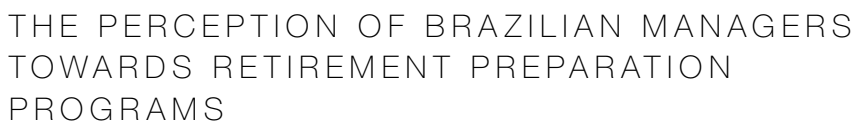

As the ageing of the Brazilian population has become more apparent, the National Policy for Aging and the Statute of the Elderly has taken a number of measures toward the well-being of this population. As part of these measures, the retirement preparation programme stands out, even though many companies do not recognize this requirement. The purpose of this research is to investigate how 207 managers - one per organization - perceive the Retirement Preparation Programme - RPP within the organization. The majority of the participants are female (60\%) with an average age of 49 years (26 to 76 years). Results have shown that even though the majority considers its implementation relevant only one quarter of the organizations have adopted the RPP. Around half of the managers feel that the programme should be offered at least 3 to 5 years before retirement. When asked about 
the measures that could be taken with the more elderly workers, the rate was greater with the measures that would not be implemented, such as: the possibility of reducing the hierarchical status (84\%), extra leave (83\%) partial retirement - part-time work (78.5\%), reduction in working schedule (72\%). The measures to be implemented would be the possibility of adapting tasks (52.2\%), ergonomic measures (50.7\%) and age limit for inappropriate or hazardous work (44.6\%). These results have shown the need to make managers more aware of ageing within the organisational context especially those from the Human Resources.

keywords

Ageing. Organisations. Managers. Retirement Preparation Programs.

\author{
referências
}

ALCOVER, Carlos-Maria; TOPA, Gabriela; FERNÁNDEZ, Juan José. Organizational management of older workers and the processes of maintaining, extending and leaving employment. Papeles del Psicólogo, Barcelona, v. 35, n. 2, p. 91-98, June 2014.

ARMSTRONG-STASSEN, Marjorie. Human resource practices for mature workers And why aren't employers using them? Asia Pacific Journal of Human Resources, Los Angeles, v. 46, n. 3, p. 334-352, Dec. 2008.

BRASIL. Lei $n^{\circ} 10.741$, de $1^{\circ}$ de outubro de 2003. Decreta e sanciona o Estatuto do Idoso. Salvador: Ministério Público do Estado da Bahia, 2003.

Lei no 8.842, de 4 de janeiro de 1994. Decreta e sanciona a Política Nacional do Idoso, cria o Conselho Nacional do Idoso e dá outras providências. Salvador: Ministério Público do Estado da Bahia, 1994.

CAHILL, Kevin; GIANDREA, Michael; QUINN, Joseph. Bridge employment. In: WANG, Mo (Org.). The Oxford Handbook of Retirement. Oxford: Oxford University Press, 2013. p. 293-310.

DORFMAN, Lorraine. Health conditions and perceived quality of life in retirement. Health \& Social Work, Washington, v. 3, n. 20, p. 192-199, Aug. 1995.

FONSECA, Antônio. Do trabalho à reforma: quando os dias parecem mais longos. Revista da Faculdade de Letras da Universidade do Porto, Porto, Número temático/2, p. $75-95,2012$.

FRANÇA, Lucia H. F. P. Repensando a Aposentadoria com Qualidade - Um manual para facilitadores em programas de educação para a aposentadoria. Rio de Janeiro: Universidade Aberta da Terceira Idade - UERJ, 2009.

. O Desafio da aposentadoria. Rio de Janeiro: Rocco, 2008. 
FRANÇA, Lucia H. F. P. et al. Atitudes dos trabalhadores de cargos não-gerenciais frente à Aposentadoria (Relatório de pesquisa). Pesquisa apoiada pela FAPERJ, APQ1 no. E-26/ 171.400/2006 e pelo CNPq no. 400527/2007-3, 2009.

Envelhecimento dos trabalhadores nas organizações: estamos preparados? In: FRANÇA, Lucia H F. P.; Dayze Stepansky. (Orgs.). Propostas multidisciplinares para o bem-estar na aposentadoria. Rio de Janeiro: Quartet: FAPERJ, p. 25-52, 2012.

Programas de Preparação para a Aposentadoria - diagnóstico e estratégias para implantação. In: MENDONÇA, Helenides; FERREIRA, Maria Cristina Ferreira. (Orgs.). Diagnóstico em organizações: teoria e prática. No prelo.

FRANÇA, Lucia H. F. P.; BENDASSOLLI, Pedro; MENEZES, Gustavo S.; MACEDO, Luciani S. Aposentar-se ou continuar trabalhando? O que influencia essa decisão? Psicologia: Ciência e Profissão, Brasília, n. 33, v. 3, ago. 2013.

INSTITUTO BRASILEIRO DE GEOGRAFIA E ESTATÍSTICA. Síntese de indicadores sociais - Uma análise das condições de vida da população brasileira. 2012. Disponíve em: <http://www.ibge.gov.br/home/presidencia/noticias/imprensa/ppts/0000000144. pdf $>$. Acesso em: 26 jun. 2014.

INSTITUTO DE PESQUISA ECONÔMICAAPLICADA. Comunicado n 157/12 - Tendências demográficas mostradas pelo PNAD 2011. 2012. Disponível em: <http://www. ipea.gov.br/portal/images/stories/PDFs/comunicado/121011_comunicadoipea157. pdf. >. Acesso em: 22 set. 2014.

KIM, Jungmeen E.; MOEN, Phyllis. Retirement transitions, gender, and psychologica well-being: A life-course, ecological model. The Journals of Gerontology, United States, v. 57, n. 3, p. 212-222, May 2002

LUBORSKY, Mark; LEBLANC, lan. Cross-cultural perspectives on the concept of retirement: An analytic redefinition. Journal of Cross Cultural Gerontology, Europe, v. 18, n. 4, p. 251-271, Dec. 2003.

MARANGONI, Jacqueline F; MANGABEIRA, Janemary Athayde. Política integrada de atenção à saúde do servidor público do Distrito Federal: o programa de preparação para o período pós-carreira. Revista Brasileira Medicina do Trabalho, Curitiba, v. 12 n. 1, p. 8-15, out. 2014

MARQUES, Sibila; BATISTA, Maria; SILVA, Pedro. A promoção do envelhecimento ativo em Portugal: preditores de aceitação de um chefe mais velho. Sociologia: Revista da Faculdade de Letras da Universidade do Porto, Porto, Número temático/2, p. 53-73, 2012.

MENEZES, Gustavo, S.; FRANÇA, Lucia H. F. P. Preditores da decisão da aposentadoria por servidores públicos federais. Revista Psicologia, Organizações e Trabalho, Florianópolis, v. 12, n. 3, dez. 2012.

MURTA, Sheila et al. Preparação para a aposentadoria: implantação e avaliação do programa viva mais! Psicologia Reflexão e Crítica, Porto Alegre, v. 27, n. 1, mar. 2014

NOONE, Jack; STEPHENS, Christine; ALPASS, Fiona. Preretirement Planning and Well-Being in Later Life: A Prospective Study. Research on Aging, Boston, v. 31, n. 3 , p. 295-317, Feb. 2009

ORGANIZAÇÃO MUNDIAL DE SAÚDE. Envelhecimento Ativo: uma política de saúde. 2005. Disponível em: <http://www.prosaude.org/publicacoes/diversos/envelhecimento_ativo.pdf>. Acessado em: 23 set. 2014. 
PALMORE, Erdman B., GEORGE, Linda K., FILLENBAUM, Gerda G. Predictors of Retirement. Journal of Gerontology, United States, v. 37, n. 6, p. 733-742, Nov. 1982.

POTOCNIC, Kristina; TORDERA, Nuria; PEIRÓ, José Maria. Truly satisfied with your retirement or just resigned? Pathways toward different patterns of retirement satisfaction. Journal of Applied Gerontology, Minnesota, v. 32, n. 2, p. 164-187, Apr. 2011.

SHACKLOCK, Kate; FULOP, Liz; HORT, Linda. Managing older worker exit and re-entry practices: A 'revolving door'? Asia Pacific Journal of Human Resources, Melbourne, v. 45, n. 2, p. 151-167, Aug. 2007.

SHULTZ, Kenneth; WANG, Mo. Psychological perspectives on the changing nature of retirement. American Psychologist, Washington, v. 66, n. 3, p. 170-179, Apr. 2011.

SOARES, Dulce P. S.; COSTA, Aline B. Aposent-ação - Aposentadoria para ação. São Paulo: Vetor, 2011.

TEH, Choo, E.The aging workforce: Some implications, strategies and policy considerations for human resource managers. Asia Pacific Journal of Human Resources, Murdoch, v. 37, n. 2, p. 60-75, July 1999.

VAN DALEN, Hendrik, HENKENS, Kène; SCHIPPERS, Joop. Productivity of Older Workers: Perceptions of Employers and Employees. Population and Development Review, v. 36, n. 2, p. 309-330, June 2010.

WANG, Mo. Retirement: An introduction and overview of the Handbook. In: Mo Wang (Org.). The Oxford Handbook of Retirement. Oxford: Oxford University Press, 2013. p. 3-9.

WANG, Mo; HENKENS, Kène; VAN SOLINGE, Hanna. Retirement adjustment: A review of theoretical and empirical advancements. American Psychologist, Washington, v. 66, n. 3, p. 204-213, Apr. 2011

ZANELLI, José Carlos; SILVA, Narbal. Programa de Preparação para Aposentadoria. Florianópolis: Insular, 1996.

ZANELLI, José Carlos; SILVA, Narbal; Soares, Dulce Penna. Orientação para aposentadoria nas organizações de trabalho: construção de projetos para o pós-carreira. Porto Alegre: ARTMED, 2010.

Recebido em: 23/09/2014

Aceite final: 20/12/2014 